\title{
Qualidade do gasto público municipal em ensino fundamental no Brasil
}

\author{
MARIA DOLORES MONTOYA DIAZ*
}

Quality of municipal public spending on primary education in Brazil. The focus of this paper was to analyze the relationship between municipal public education spending and students' academic achievement, evaluated according to IDEB (Index of Basic Education Development) of 2005. The following databases were used: School Census 2005, Brazil Exam (mathematics evaluation applied to students from fourth grade of elementary school) and Finance of Brazil (FINBRA). A multilevel model was estimated and the results suggest that simply increasing the percentage of municipal expenditures on education or the percentage of spending on primary education in relation to municipal expenditures on education do not automatically guarantee improvements in the quality of education.

Keywords: municipal public expenditure on primary education; efficiency; economics of education; Brazil.

JEL Classification: H52; I28; C21.

\section{INTRODUÇÃO}

O debate a respeito da efetividade dos recursos aplicados nas instituições de ensino teve como importante marco o ano de 1966 quando foi divulgado nos Estados Unidos um relatório intitulado Equality of Educational Opportunity, que ficou conhecido como "Coleman Report”.

\footnotetext{
* Departamento de Economia da Faculdade de Economia e Administração da Universidade de São Paulo. E-mail: madmdiaz@usp.br. Este trabalho foi resultado de projeto realizado pela Fipe para o ETCO - Instituto Brasileiro de Ética Concorrencial. Agradeço os comentários e críticas dos participantes de seminário de discussão dos resultados do projeto realizado na FEA/USP, especialmente aos Profs. André F. Montoro Filho e Hélio Zylberstajn. Sou grata, ainda, a dois pareceristas anônimos da Revista de Economia Política. Eventuais erros e omissões do texto são, entretanto, de exclusiva responsabilidade da autora. Submetido: 7/setembro/2008; Aprovado: 18/junho/2010.
} 
Genericamente, o estudo tinha por objetivo avaliar aspectos equitativos do sistema de ensino americano. Para tanto, foram utilizadas informações de $600 \mathrm{mil}$ alunos vinculados a mais de três mil escolas. A abordagem utilizada era bastante original para a época já que procurava explicar as diferenças existentes no desempenho dos alunos, pela análise da relação entre os insumos e o produto final, ou seja, procurava, de certo modo, identificar uma função de produção existente nas escolas. Conforme Harbison e Hanushek (1992), entretanto, o relatório acabou ficando mais conhecido pela sua conclusão do que pela metodologia inovadora. Essencialmente, os resultados indicavam que os fatores explicativos mais importantes para o desempenho escolar dos estudantes eram a família, em primeiro lugar, e a seguir, os colegas, relegando um papel insignificante para a escola. Deste modo, iniciou-se um polarizado debate que não se restringiu aos círculos acadêmicos, ou políticos, mas se disseminou pela sociedade, acerca da efetiva contribuição dos recursos escolares para o aprendizado dos alunos.

Dois nomes se destacaram na literatura sobre o tema: Erik A. Hanushek, defendendo a posição de que simplesmente "mais dinheiro não faz diferença", e Alan B. Krueger, que critica as análises realizadas por Hanushek para embasar sua opinião e acaba por defender algumas das políticas de aumento de recursos para as escolas (por ex., redução da relação alunos/docentes).

Uma interessante tentativa de obter alguns pontos de consenso que permitam o encaminhamento da discussão de modo menos passional e mais produtivo pode ser encontrada em Rothstein (2000), na qual o autor introduz um debate entre Hanushek e Krueger sobre a questão das políticas de redução dos tamanhos das turmas. No seu texto ele procura identificar pontos de concordância nos textos dos autores. Por exemplo, ao citar afirmações de cada um dos autores, o autor conclui que:

All should be able to agree that some schools have spent their funds effectively, and others have not. All should be able to agree that targeting the expenditure of new funds in ways that have proven to be effective is far preferable to "throwing money at schools" without regard to how it will be spent. All should be able to agree that there is strong reason to suspect that minority and disadvantaged children can benefit more than others from a combination of smaller class sizes and more effective teachers. And all should be able to agree that much more research is needed to understand precisely what the most effective expenditures on schools and other social institutions might be if improving student achievement and narrowing the gap in achievement between advantaged and disadvantaged children are the goals. It is difficult to avoid the conclusion that continued debates about whether money in the abstract makes a difference in education, without specifying how it might be spent, are unproductive. Equally true, denying that specific resource enhancements, alongside policy changes, can be an essential part of any reform agenda is also unproductive. Hopefully, the Krueger-Hanushek dialogue that follows can help to focus future debates on where spending is more effective. (pág. 4) 
É interessante destacar, por outro lado, que apenas recentemente verifica-se a chegada desta discussão ao Brasil.

Por um lado, os pífios resultados obtidos por estudantes brasileiros em avaliação internacional de desempenho escolar conduzida pela OCDE - Organização para Cooperação Econômica e Desenvolvimento, conhecido como o PISA (Programme for International Student Assessment), suscitam o argumento fácil de que decorrem dos baixos investimentos em educação. Basta verificar, por exemplo, matérias publicadas em jornais sobre a divulgação do relatório anual de 2007 da OCDE sobre educação (Education at a Glance): País segue em último no investimento em Educação (O Estado de São Paulo, 19/09/2007) e Brasil é o que menos investe em educação (Folha de São Paulo, 19/09/2007). Em ambas, o destaque é para uma das estatísticas apresentadas no relatório relativa ao gasto médio anual por aluno em 2004, considerando desde o ensino fundamental até o universitário, que, no caso do Brasil, seria de US\$1.303,00 enquanto os Estados Unidos, que apresentou o maior valor entre os 34 países analisados, foi de US\$12.092,00. Ocorre, entretanto, que este é apenas um dos aspectos analisados, e que se encontra perfeitamente contextualizado no relatório junto a um grande conjunto de outras informações sobre investimento em educação. É importante destacar que, no caso, brasileiro, a informação acima se refere apenas ao gasto público, o que não incorpora, portanto, um grande volume de recursos relativo ao gasto privado em educação.

Por outro lado, verifica-se um crescente descontentamento com a tendência ascendente da carga tributária brasileira, apontada por muitos economistas e empresários como fator de desestímulo ao investimento privado e, consequentemente, do baixo crescimento da economia.

Nesta linha, seria possível enfocar as estatísticas sobre gastos, também produzidas pela OCDE, de outro modo, o que nos levaria exatamente à conclusão oposta, ou seja, de que as despesas com educação no Brasil não são pequenas. Pode-se ver na Tabela 1 que, entre o grupo dos países que participaram do PISA em 2003, o Brasil situa-se entre aqueles que, proporcionalmente em relação ao PIB, foi um dos que mais gastou com educação em 2003. Deve-se notar que se optou por construir a tabela com dados do referido ano pela necessidade de compatibilização com a fonte de informações dos gastos privados brasileiros que é a Pesquisa de Orçamentos Familiares IBGE, 2002-2003, a mais recente disponível.

Tabela 1: Gasto em Educação como \% PIB - 2003

\begin{tabular}{|l|c|c|c|}
\hline \multicolumn{1}{|c|}{ Países } & Público 1 & Privado & $\begin{array}{c}\text { Gasto Total } \\
\text { em Educação: } \\
\text { \% PIB (Público e } \\
\text { Privado) }-2003\end{array}$ \\
\hline Islândia & 7,5 & 0,5 & 8,0 \\
\hline Coreia & 4,6 & 2,9 & 7,5 \\
\hline Estados Unidos & 5,4 & 2,1 & 7,5 \\
\hline Dinamarca & 6,7 & 0,3 & 7,0 \\
\hline Nova Zelândia & 5,7 & 1,2 & 6,8 \\
\hline
\end{tabular}




\begin{tabular}{|c|c|c|c|}
\hline México & 5,6 & 1,2 & 6,8 \\
\hline Suécia & 6,5 & 0,2 & 6,7 \\
\hline Noruega & 6,5 & 0,1 & 6,6 \\
\hline Brasil & 4,4 & $2,2 a$ & 6,6 \\
\hline Suíça & 6,0 & 0,6 & 6,5 \\
\hline Polônia & 5,8 & 0,7 & 6,4 \\
\hline França & 5,8 & 0,5 & 6,3 \\
\hline OECD total & 4,9 & 1,3 & 6,3 \\
\hline Finlândia & 6,0 & 0,1 & 6,1 \\
\hline Bélgica & 5,9 & 0,2 & 6,1 \\
\hline Hungria & 5,5 & 0,6 & 6,1 \\
\hline Reino Unido & 5,1 & 1,0 & 6,1 \\
\hline Canadá & 4,6 & 1,3 & 5,9 \\
\hline Portugal & 5,8 & 0,1 & 5,9 \\
\hline OECD média & 5,2 & 0,7 & 5,9 \\
\hline Austrália & 4,3 & 1,5 & 5,8 \\
\hline Áustria & 5,2 & 0,3 & 5,5 \\
\hline Alemanha & 4,4 & 0,9 & 5,3 \\
\hline Itália & 4,6 & 0,4 & 5,1 \\
\hline Países Baixos & 4,6 & 0,4 & 5,0 \\
\hline Japão & 3,5 & 1,2 & 4,8 \\
\hline República Eslovaca & 4,3 & 0,5 & 4,7 \\
\hline República Tcheca & 4,3 & 0,4 & 4,7 \\
\hline Espanha & 4,2 & 0,5 & 4,7 \\
\hline Irlanda & 4,1 & 0,3 & 4,4 \\
\hline Grécia & 4,0 & 0,2 & 4,2 \\
\hline Turquia 2 & 3,6 & 0,1 & 3,7 \\
\hline
\end{tabular}

1. Inclui subsídios públicos para domicílios destinados a instituições educacionais e despesas diretar em instituições educacionais oriundas de fontes internacionais.

2. Ano de referência: 2002.

3. Ano de referência: 2004.

a. Estimativas obtidas a partir de informações obtidas no site do IBGE, sobre gastos totais privados em educação e em Castro e Monteiro Vaz (2007, p. 91).

Fonte: OCDE. Education at a Glance 2006. Indicador B2 (www.oecd.org/edu/eag2006).

No Gráfico 1: pode-se ver uma comparação entre os gastos como \% do PIB dos vários países e o resultado padronizado médio em matemática obtido pelos estudantes de 15 anos de idade de cada um dos países. É realmente constrangedor verificar que o Brasil ficou em último lugar. E o pior, mantendo a enorme distância em relação a países de nível de desenvolvimento semelhante que havia sido verificada na primeira rodada de avaliações realizada no ano de 2000. 


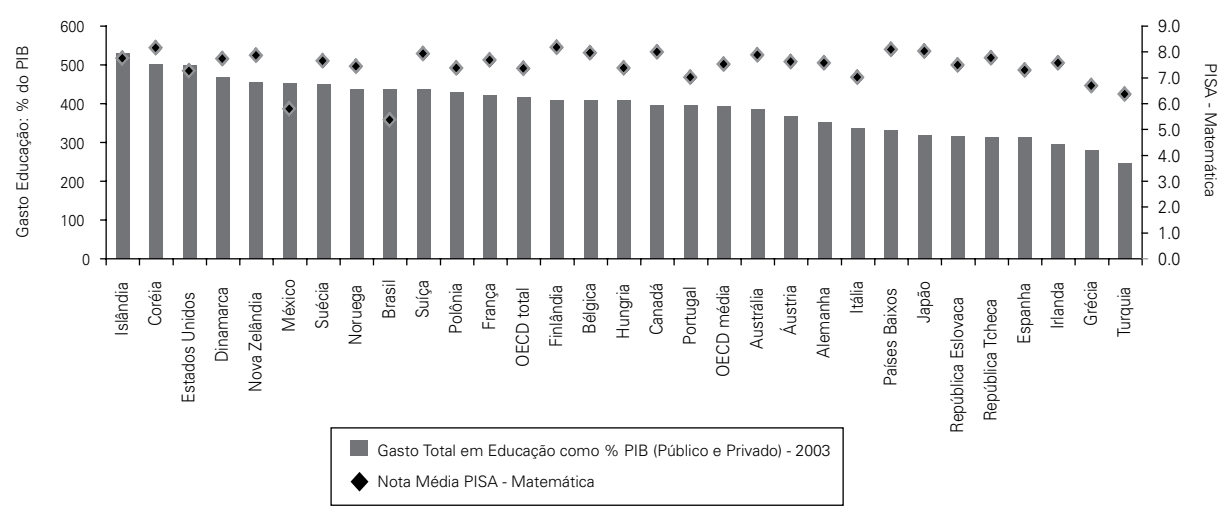

A partir da contextualização apresentada pretende-se a seguir discutir a qualidade dos gastos municipais por aluno do ensino fundamental em escolas municipais brasileiras. E qualidade será aqui entendida como fator claramente associado a melhorias dos resultados obtidos. ${ }^{1}$

Os resultados de interesse serão representados pelo IDEB — Índice de Desenvolvimento da Educação Básica, que é um indicador elaborado pelo MEC e "que combina informações de desempenho em exames padronizados (Prova Brasil ou Saeb) - obtido pelos estudantes ao final das etapas de ensino $\left(4^{a}\right.$ e $8^{a}$ séries do ensino fundamental e $3^{\text {a }}$ série do ensino médio) - com informações sobre rendimento escolar (aprovação)". Essencialmente, o IDEB resulta do produto entre o desempenho nos testes padronizados e inverso do tempo médio para conclusão de uma série. ${ }^{2}$

No caso, foi utilizado o IDEB relativo às séries iniciais do Ensino Fundamental. No Gráfico 2 pode-se verificar que também não é óbvia a relação entre maiores gastos municipais e resultado escolar. Entre as capitais, notam-se situações como as de Rio Branco, Florianópolis e Porto Alegre, com gastos por aluno mais elevados e desempenho médio no IDEB inferior, por exemplo, a Curitiba. Entre municípios com mais de 500 mil habitantes, observa-se o mesmo quadro, ou seja, com bons resultados obtidos por São José dos Campos, Sorocaba e São Bernardo, por exemplo, que estão associados a distintos níveis de gastos médios municipais.

Estas informações gerais mostram claramente como as avaliações sobre o nível dos gastos em educação são bem mais complexas do que os resultados e comentá-

\footnotetext{
${ }^{1}$ Nesta mesma linha, os relatórios da OCDE procuram analisar detalhadamente vários aspectos adicionais na comparação entre países, como, por exemplo, gastos por esfera governamental, por nível etc.

${ }^{2}$ A escala dos valores do IDEB pode ser mais bem compreendida pelo seguinte exemplo: para uma escola A cuja média padronizada da Prova Brasil, $4^{a}$ série, é 5,0 e o tempo médio de conclusão de cada série é de 2 anos, a rede/escola terá o Ideb igual a 5,0 multiplicado por $1 \frac{1}{2}$, ou seja, Ideb $=2,5$. Já uma escola B com média padronizada da Prova Brasil, $4^{a}$ série, igual a 5,0 e tempo médio para conclusão igual a 1 ano, terá Ideb $=5,0$. Informações retiradas da Nota técnica sobre o IDEB obtida em: http:// ideb.inep.gov.br/Files/Site/Download/Nota_Tecnica_IDEB.pdf.
} 
rios, frequentemente apresentados, pretendem fazer parecer. A este respeito, vale destacar que o reconhecimento sobre esta complexidade permeia todo o relatório apresentado pela OCDE. Veja-se, por exemplo, o texto sobre o contexto político, que acompanha os resultados sobre investimento anual médio por aluno:

Effective schools require the right combination of trained and talented personnel, adequate facilities, and motivated students ready to learn. The demand for high-quality educatqion, which can translate into higher costs per student, must be balanced against placing undue burden on taxpayers. ${ }^{3}$

Gráfico 2: Gasto Municipal Médio Anual por Aluno e IDEB (2005)

(a) Capitais

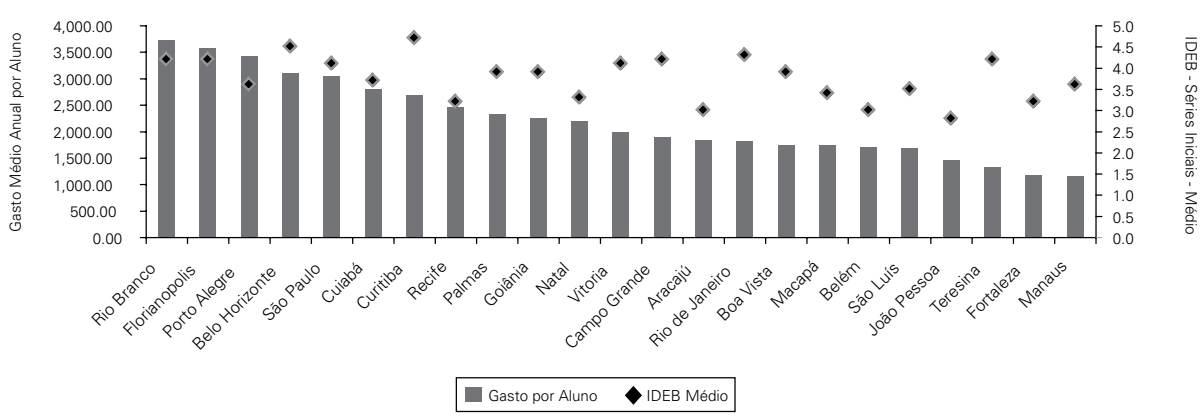

(b) Municípios com mais de 500 mil habitantes

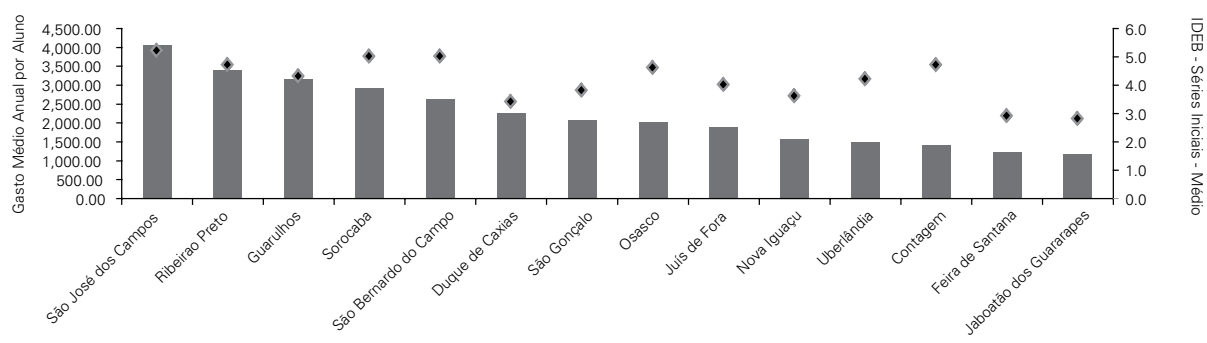

Gasto por Aluno IDEB Médio

Deste modo, pretende-se neste texto contribuir neste debate sobre a qualidade do gasto público municipal em educação, especificamente com ensino fundamental no Brasil, por meio da análise sobre a existência ou não de relação entre os gastos municipais em educação e os resultados de suas redes, avaliados de acordo com IDEB obtido no ano de 2005.

Para tanto, torna-se necessário controlar aspectos relativos às características

${ }^{3}$ Education at a Glance 2007. OECD INDICATORS. 
das escolas e práticas pedagógicas que podem interferir nos níveis de aprendizagem dos estudantes.

\section{METODOLOGIA E VARIÁVEIS UTILIZADAS}

Recentemente, em muitas áreas das ciências sociais tem sido dada especial atenção à necessidade de incorporar os efeitos das conexões existentes entre os indivíduos e as características do ambiente onde os mesmos vivem e desenvolvem suas atividades. Como lembraram Rice e Jones (1997), tem sido mais cuidadosas, principalmente na área de economia, as avaliações sobre a relação existente entre os indivíduos e as características das instituições às quais eles pertencem ou do contexto onde estão inseridos, principalmente na avaliação da efetividade ou da performance de instituições públicas.

Como destacado em Diaz (2007), os modelos tradicionalmente utilizados apresentam limitações quando utilizados na análise de dados que apresentam uma estrutura hierárquica, como aqueles encontrados nos estudos baseados em pesquisas domiciliares, cuja estrutura é indivíduo/domicílio/estado/região, ou mesmo na análises de dados educacionais, com alunos agrupados em classes dentro de escolas, ou mesmo de escolas dentro de municípios. A metodologia a ser aplicada, ou seja, dos modelos multinível permite investigar simultaneamente efeitos individuais e efeitos contextuais, bem como acomodar a correlação intragrupo e modelar estruturas complexas de variância. ${ }^{4}$

Adicionalmente, a adoção desta metodologia segue a mesma linha adotada por Franco et al. (2007), cujo foco de análise é a identificação de características escolares promotoras da eficácia e da equidade intraescolar. Deste modo, procurou-se, sempre que possível, balizar a especificação dos modelos a serem estimados pelos resultados encontrados no referido trabalho.

A especificação final adotada foi a de um modelo hierárquico com dois níveis (escolas e municípios) e com intercepto aleatório.

\section{BASES DE DADOS}

Foram utilizadas as seguintes bases de dados: Censo Escolar de 2005, Prova Brasil (avaliação de matemática aplicada a alunos de quarta série do ensino fundamental) e FINBRA.

\footnotetext{
${ }^{4}$ Em termos genéricos, a existência de correlação entre os indivíduos pertencentes a um mesmo grupo, por exemplo, entre alunos de uma mesma escola, pacientes de um mesmo médico, escolas de um mesmo município etc. gera um viés negativo nas estimativas dos erros-padrão dos parâmetros do modelo estimado pelo Método de Mínimos Quadrados Ordinários conforme provado por Goldstein (1995). Porém, o que se pretende a partir da metodologia associada à construção e estimação dos Modelos Multinível não se resume simplesmente à obtenção de erros-padrão "corretos" ou "corrigidos", produzidos facilmente, por exemplo, pelo método de Mínimos Quadrados Generalizados, como ocorre nos modelos convencionais, quando se identifica a presença de autocorrelação ou heterocedasticidade do termo aleatório. Maiores detalhes podem ser encontrados em Diaz (2007).
} 
O Censo Escolar é realizado anualmente pelo Instituto Nacional de Estudos e Pesquisas Educacionais Anísio Teixeira (Inep/MEC), em parceria com as secretarias estaduais e municipais de Educação. São coletadas diversas informações sobre a Educação Básica, em seus diferentes níveis, Educação Infantil, Ensino Fundamental e Ensino Médio - e modalidades, Ensino Regular, Educação Especial e Educação de Jovens e Adultos, nas redes pública e privada, como, por exemplo, número de matrículas, dados sobre professores e sobre a infraestrutura das escolas. No Censo foram obtidas informações sobre práticas escolares, como percentual de livros reaproveitados de $4^{a}$ série, sobre formação dos professores e sobre a infraestrutura escolar (existência de laboratório de informática, biblioteca etc.) por escola.

A Prova Brasil é uma avaliação de rendimento escolar aplicada a alunos de escolas públicas. Compõe o Sistema Nacional de Avaliação da Educação Básica (Saeb) e foi desenvolvida e realizada pelo Instituto Nacional de Estudos e Pesquisas Educacionais Anísio Teixeira (Inep/MEC). De acordo com informações obtidas no INEP $^{5}$ sua primeira aplicação ocorreu em novembro de 2005 e foi realizada em 5.387 municípios de todas as unidades da Federação, avaliando 3.392.880 alunos de $4^{a}$ e $8^{a}$ séries do ensino fundamental, distribuídos em 125.852 turmas de 40.962 escolas públicas urbanas com mais de 30 alunos matriculados na série avaliada. Foram aplicadas provas de Língua Portuguesa (com foco em leitura) e Matemática. É importante destacar que, além das provas, os alunos responderam a um questionário que coletou informações sobre seu contexto social, econômico e cultural. Foram utilizadas as informações sobre o perfil socioeconômico dos estudantes obtidas na base relativa às provas de matemática aplicadas aos alunos de $4^{a}$ série.

A base de dados mais completa disponível sobre finanças públicas municipais e estaduais é conhecida como FINBRA - Finanças do Brasil e é realizada pela Secretaria do Tesouro Nacional. Nela podem ser encontradas informações sobre execução orçamentária (receita e despesa) e de balanço patrimonial (ativo e passivo). É importante notar que esta base torna disponível dados sobre despesas classificadas de acordo com função e subfunção programática, que no caso da área de educação permitem a obtenção da seguinte desagregação: Despesa Total Municipal em Educação que resulta da soma das Despesas com: Ensino Fundamental, Ensino Médio, Ensino Profissional, Ensino Superior, Educação Infantil, Educação de Jovens e Adultos, Educação Especial e Outras Despesas na Função Educação. Deste modo, foi possível obter o nível de despesas em educação, com identificação sobre os recursos alocados ao ensino fundamental. Assim, foram construídos alguns indicadores sobre critérios de alocação dos recursos municipais como percentual das despesas com educação relativamente às despesas totais ou percentual das despesas com ensino fundamental sobre as despesas com educação.

Finalmente, foram obtidos no site do INEP $^{6}$ dados sobre o IDEB de cada uma das escolas municipais relativos ao desempenho dos alunos de $4^{a}$ série.

\footnotetext{
${ }^{5}$ http://www.inep.gov.br/basica/saeb/prova_brasil/.

${ }^{6}$ http://ideb.inep.gov.br/Site/download_1.php.
} 
Foram analisadas 12969 escolas municipais de todo o país, situadas em 2910 municípios brasileiros. $^{7}$

Verificou-se que o valor médio do IDEB para as séries iniciais das escolas analisadas foi aproximadamente 3,76, atingindo o valor máximo de 7,3. Relativamente à variável caracterizadora do atraso escolar, constatou-se que em média, o percentual de alunos que possuem 11 ou mais anos de idade na $4^{\mathrm{a}}$ série foi de 50,68\%. Em relação à escolaridade dos pais, os resultados indicaram uma média inferior a $20 \%$ de alunos cujas mães (pais) nunca estudaram ou não haviam completado a $4^{a}$ série. É importante notar, entretanto, que ambos os casos há escolas em que esse percentual é de $100 \%$. A média da variável que reflete o percentual de alunos que realizaram a Prova Brasil de Matemática em cada escola que mencionou participar do programa Bolsa Família foi 31,76\%.

Em se tratando do perfil das escolas, verificou-se que aproximadamente $85 \%$ das escolas possuíam sistema de filtragem da água a ser consumida pelos alunos, menos da metade, possuíam biblioteca e uma proporção pequena possuía sala de leitura $(23 \%)$ e/ou laboratório de informática $(30 \%)$.

Por outro lado, é interessante notar o elevado percentual $(89,6 \%)$ da variável que reflete a prática escolar de reaproveitamento de livros didáticos, indicando que a maior parte das escolas da amostra adota este procedimento.

Em se tratando dos gastos públicos municipais, verificou-se que o percentual médio das despesas com educação em relação às despesas totais foi $27,06 \%$ e o percentual médio das despesas com ensino fundamental sobre as despesas com educação foi $78,44 \%$.

Tabela 2: Percentuais da variável Gasto Municipal por Aluno

\begin{tabular}{|c|c|}
\hline Percentuais & Gasto aluno \\
\hline $1 \%$ & 614.68 \\
\hline $5 \%$ & 703.03 \\
\hline $10 \%$ & 814.98 \\
\hline $25 \%$ & $1,144.71$ \\
\hline $50 \%$ & $1,817.42$ \\
\hline $75 \%$ & $2,417.49$ \\
\hline $90 \%$ & $3,043.25$ \\
\hline $95 \%$ & $3,437.72$ \\
\hline $99 \%$ & $4,675.80$ \\
\hline
\end{tabular}

$\mathrm{Na}$ 6,82, encontra-se informação adicional acerca da distribuição da variável gasto municipal por aluno. Assim, constata-se que na amostra analisada a mediana do gasto municipal por aluno foi em 2005 de R \$1.817,42 enquanto a média atin-

\footnotetext{
${ }^{7} \mathrm{O}$ Quadro com a definição das variáveis, bem como a Tabela que contém as estatísticas descritivas encontra-se na versão eletrônica deste trabalho.
} 
giu R\$1.890,83. O percentil mais baixo, ou seja, que delimita $1 \%$ dos valores menores foi de $\mathrm{R} \$ 614,68$ enquanto o valor mais elevado foi $\mathrm{R} \$ 9,810.20$.

\section{RESULTADOS}

Deve-se notar que o objetivo deste trabalho é verificar se as variáveis relativas aos gastos públicos (percentual das despesas com educação em relação a despesas totais do município, percentual das despesas com ensino fundamental em relação ao total das despesas com educação, gasto municipal anual por aluno, entre outras) são estatisticamente significativas e com sinais positivos, controlados os demais aspectos que teoricamente também afetariam o desempenho escolar e que representam o perfil do alunado (percentual de alunos com atraso escolar, com pais de baixa escolaridade, que participam do programa bolsa família, etc.), características do corpo docente e da escola (número de docentes, percentual de docentes com ensino médio-magistério, se possui biblioteca, água filtrada etc.), características do município (população, se o município é capital etc.).

Sendo assim, serão comentados, inicialmente, os resultados relativos à significância estatística das variáveis de controle, antes que sejam analisados os resultados finais relacionados às variáveis relativas aos gastos públicos municipais.

Conforme esperado, as variáveis caracterizadoras do perfil do alunado (percentuais de alunos que possuem 11 ou mais anos de idade na 4a série e percentuais de alunos cujas mães ou pais nunca estudaram ou não haviam completado a $4^{\mathrm{a}}$ série) apresentaram sinal negativo. Em relação à variável relativa ao percentual de alunos que declararam fazer parte do programa Bolsa Família, deve-se mencionar a possibilidade de ser interpretada como indicadora de renda. Assim, quanto mais elevado é o percentual, provavelmente, mais pobre será a comunidade atendida pela escola, considerando que o programa esteja bem focalizado. Deste modo, o resultado negativo acompanharia aqueles representados pelas variáveis relativas à baixa escolaridade dos pais. ${ }^{8}$

Também, de acordo com o esperado, verificou-se que a variável relativa à posse de computador com acesso à internet em casa apresentou sinal positivo e também pode ser entendida como indicadora de condição socioeconômica da família.

Características do corpo docente também produziram efeitos significativos. Assim, o percentual de docentes sem ensino superior apresentou impactos negativos.

\footnotetext{
${ }^{8}$ Este comentário faz-se necessário para evitar a interpretação comum de que o coeficiente negativo evidenciaria o fracasso do programa em relação ao objetivo de melhorar o desempenho escolar das crianças beneficiárias do programa. Para este tipo de conclusão acerca da causalidade existente entre o programa e o desempenho escolar seria necessária a adoção de uma estratégia de modelagem específica para responder à questão: o que teria acontecido com o desempenho dos alunos que participaram do programa caso não tivessem participado? Obviamente, como não é possível obter a informação sobre fato não ocorrido, essencialmente, deve-se procurar comparar resultados de participantes e não participantes do programa que apresentem características semelhantes. Justamente, nesta etapa surgem as maiores dificuldades. Deste modo, este tipo de avaliação foge totalmente do escopo deste trabalho.
} 
Relativamente às práticas pedagógicas foi muito interessante notar que quanto maior o percentual de livros reaproveitados de $4^{a}$ série, maior o valor do IDEB da escola. Na verdade, esta variável parece captar uma prática de engajamento coletivo, que se reflete no cuidado e aproveitamento máximo dos recursos disponíveis na escola.

Em relação às características da escola, verificou-se que a disponibilidade de água filtrada para o consumo dos alunos, a existência de biblioteca e de sala de leitura apresentaram impactos positivos sobre os resultados do IDEB.

As variáveis relativas à existência de laboratório de informática ou a forma de acesso dos alunos a computadores - acompanhados ou não por professores — não se mostraram estatisticamente significativas, indicando que estes recursos não parecem influenciar o desempenho escolar medido pelo IDEB.

Interessante notar, ainda, que escolas maiores, representadas pelo maior número de professores também se mostraram relevantes, porém, com impacto negativo sobre os resultados medidos pelo IDEB.

Finalmente, relativamente às medidas de gastos verificaram-se dois resultados distintos: sinal positivo para a variável gasto municipal por aluno, apesar de dimensão muito pequena, indicando que quanto maior o gasto municipal por aluno maior é o valor do IDEB esperado e sinais negativos tanto para o percentual das despesas com educação em relação às despesas municipais totais como para o percentual das despesas com ensino fundamental em relação às despesas com educação.

Estes resultados parecem indicar a existência de um pequeno impacto positivo do gasto municipal por aluno. Porém, quando se avaliam os gastos gerais, refletidos nas variáveis percentuais analisadas, verifica-se que estas variáveis refletem opções políticas que não necessariamente são acompanhadas por mudanças em aspectos que diretamente afetariam as condições ou os fatores que efetivamente são responsáveis pela melhoria da qualidade do ensino público municipal. Assim, os resultados parecem indicar que simples aumentos de gastos com educação não necessariamente causam melhoria da qualidade de ensino, conforme mensurada pelo IDEB.

É interessante notar que, em geral, os resultados coincidem com aqueles apresentados por Franco et al. (2007, p. 294). Essencialmente os autores "enfatizam que a escola faz diferença, em especial por meio do clima acadêmico da escola, [...] via variáveis que enfatizavam a ênfase em passar e corrigir dever de casa, a organização de um cantinho de livros dentro da sala de aula e a manutenção de um bom clima disciplinar, da liderança do diretor, que induzia a colaboração entre professores, e da disponibilidade de recursos na escola, captada via variáveis que mensuravam tanto a disponibilidade e conservação de equipamentos quanto a existência de pessoal e de recursos financeiros na escola".

Franco et al. (2007, p. 294) ressaltam, ainda, que os resultados de sua análise indicaram "que variáveis associadas ao aumento de médias escolares também se associaram ao aumento da desigualdade dentro da escola". Deste modo, concluem que "as políticas de qualidade em educação precisam ser acompanhadas por políticas de equidade intraescolar, sem o pressuposto que políticas de qualidade equacionem automaticamente todas as dimensões da equidade”. 


\section{CONSIDERAÇÕES FINAIS}

Os resultados obtidos acima indicam que o simples aumento percentual dos gastos municipais com educação ou mesmo do percentual de gastos com educação fundamental em relação aos gastos municipais com educação não garantem automaticamente a melhoria na qualidade do ensino. Obviamente, a partir desta conclusão não se pretende afirmar que sem recursos é possível atingir níveis de qualidade e equidade desejados para nossas escolas.

O ponto é outro. O que se pretende destacar é que maiores gastos não necessariamente são acompanhados por mudanças em aspectos que afetam diretamente as condições ou fatores que efetivamente são responsáveis pela melhoria da qualidade do ensino público municipal. Assim, antes de elevar gastos é preciso identificar com a devida precisão quais aspectos devem ser alterados, e somente, então, avaliar quais recursos seriam necessários para promover as transformações necessárias. Avaliações de resultados devem ser feitas constantemente para verificar se os objetivos estão sendo alcançados.

Exemplo deste tipo de análise pode ser encontrado em Menezes-Filho e Pazello (2004) que procuraram estudar os impactos da adoção em 1998 do FUNDEF (Fundo para Manutenção e Desenvolvimento do Ensino Fundamental e Valorização do Magistério) sobre a proficiência dos alunos. Os autores concluíram que:

[...] on average, FUNDEF raised the public school teachers' relative wages and improved the relative proficiency of the public school students. Some indirect evidence was presented that showed that the effect of FUNDEF on proficiency seems to be related to its effect on wages and on school characteristics. The effect on proficiency seems to be concentrated in the municipal schools in the Northeast of the country. (págs. 16-17)

Por outro lado, é interessante conhecer também como se lida com problemas do sistema educativo em outros países. Em artigo publicado no jornal O Estado de São Paulo em 29 de abril de 2007, Norman Gall, diretor executivo do Instituto Fernand Braudel de Economia Mundial, procurou relatar suas observações sobre as reformas implantadas no sistema educativo nova-iorquino, justamente com o objetivo de melhorar o desempenho escolar na cidade. Essencialmente, Gall sintetiza as reformas em seis tópicos: mais autoridade para os diretores - e mais prestação de contas, aumentar a supervisão na sala de aula e fornecer professores altamente capacitados, contínuo processo de aplicação de exames e de avaliação, adoção de medidas de combate à violência, indisciplina e desordem nas escolas, estímulo ao envolvimento dos pais e estímulo ao maior engajamento do setor privado na educação pública. Segundo Gall, as condições melhoram lentamente. E, assim, verifica-se que o processo de mudança é difícil, pois atinge interesses e exige alterações em práticas e hábitos arraigados. Constata-se, deste modo, que destinar mais recursos a instituições ou a sistemas com problemas estruturais certamente não produzirá os resultados esperados. 
Nesta mesma linha, um estudo realizado pela Consultoria McKinsey \& Company ${ }^{9}$ entre maio de 2006 e março de 2007 com o objetivo de entender profundamente o que distingue alguns sistemas educacionais, fazendo com que sejam bem-sucedidos em nível mundial. A identificação dos casos de sucesso foi baseada nos resultados obtidos no PISA. Em termos gerais, os autores sintetizaram em três aspectos os determinantes do sucesso. São eles:

1. garantir que apenas os indivíduos mais talentosos possam candidatar-se a vagas de professor. Na Finlândia, os professores são recrutados entre os melhores alunos, ou seja, aqueles, cujo desempenho esteve entre os $10 \%$ mais elevado. A Coreia do Sul é ainda mais rigorosa, pois seleciona os docentes entre os alunos que se situam no grupo dos $5 \%$ com notas mais elevadas.

2. garantir que estes alunos talentosos possam tornar-se professores competentes. Para tanto, algumas práticas bem-sucedidas foram identificadas. Pode ser citada como exemplo, a adoção de programas de estágio nas escolas para alunos dos cursos de pedagogia, sempre associados a esquemas organizados de tutorias em que cada futuro professor tem suas atividades acompanhadas por um docente experiente que procura apontar eventuais falhas e orientar sobre os procedimentos adotados. Outra prática reportada foi a criação de incentivos para que os docentes possam aprender uns com os outros, por meio, do planejamento conjunto de aulas, da avaliação coletiva dos resultados etc.

3. garantir que cada aluno individualmente possa se beneficiar da qualidade dos professores e de toda a estrutura escolar. Assim, os processos são desenhados de modo a estabelecer metas elevadas de aprendizagem para cada aluno e avaliar o desempenho de tal modo a que intervenções (aulas especiais de recuperação, por exemplo) possam ser adotadas quando este se afasta da meta estabelecida.

Finalmente, merecem atenção também os resultados obtidos por Ribeiro e Rodrigues Jr. (2006) em uma avaliação comparativa de medidas de desempenho dos serviços públicos e eficiência dos gastos governamentais entre países latino-americanos. Apesar de algumas limitações da metodologia utilizada, inclusive mencionadas pelos autores, sobre a dificuldade de separar os efeitos do gasto público de outras influências ou fatores determinantes, é interessante verificar que os resultados obtidos indicaram que quando considerados cinco indicadores de desempenho (administração, educação, saúde, estabilidade e desempenho econômico) oito países apresentaram desempenho destacado: Chile, Costa Rica, El Salvador, Guatemala, México, Panamá, República Dominicana e Trinidad e Tobago. "O Brasil aparece na penúltima colocação (vigésimo entre os 21 países considerados, com score igual a 0,613 ) podendo economizar em torno de $40 \%$ de seus recursos sem alterar os resultados de seus indicadores." ${ }^{10}$ Com este resultado, o Brasil aparece

\footnotetext{
${ }^{9}$ Barber e Mourshed (2007).

${ }^{10}$ Ribeiro e Rodrigues Jr. (2006, p. 52).
} 
apenas à frente da Colômbia que poderia economizar aproximadamente $50 \%$ de seus insumos, produzindo os mesmos resultados.

Para concluir, devem ser destacadas as conclusões apresentadas no relatório anual de 2007 da OCDE sobre educação (Education at a Glance), que infelizmente não receberam o devido destaque no Brasil.

A análise aplica metodologia semelhante à adotada por Ribeiro e Rodrigues Jr. (2006), com a diferença de que o estudo da OCDE pretende avaliar a relação existente gastos por aluno e desempenho dos alunos dos vários países da OCDE que participaram do PISA 2003. Os resultados indicaram que apenas $15 \%$ da variação no desempenho médio dos alunos de cada um dos países pode ser explicada pelas variações nos gastos por aluno. Assim, a mensagem é a seguinte:

In summary, the results suggest that, while spending on educational institutions is a necessary prerequisite for the provision of high-quality education, spending alone is not sufficient to achieve high levels of outcomes and the effective use of these resources is important in achieving good outcomes." 11

\section{REFERÊNCIAS BIBLIOGRÁFICAS}

BARBER, Michael e MOURSHED, Mona (2007) How the world's best-performing school systems come out on top. Consultoria McKinsey \& Company. [http://www.mckinsey.com/locations/ukireland/publications/pdf/Education_report.pdf], pp. 1-50.

CASTRO, J. A. de e MONTEIRO VAZ, F. (2007). "Gastos das famílias com educação”, in Fernando Gaiger Silveira, Luciana Mendes Servo, Tatiane Menezes e Sérgio Francisco Piola (Orgs.) Gasto e Consumo das Famílias Brasileiras Contemporâneas (volume 1). DF: IPEA.

DIAZ, M. D. M. (2007) "Efetividade no ensino superior brasileiro: aplicação de modelos multinível à análise dos resultados do Exame Nacional de Cursos”. Revista Economia (ANPEC), v. 8, n. 1, pp. 99-127, jan/abr.

FRANCO, C., ORTIGAO, I., ALBERNAZ, A., BONAMINO, A., AGUIAR, G., ALVES, F. e SÁTYRO, N. (2007) "Qualidade e equidade em educação: reconsiderando o significado de 'fatores intra-escolares””. Ensaio: aval.pol.públ.Educ., Rio de Janeiro, v. 15, n. 55, pp. 277-298.

GOLDSTEIN, H. (1995) Multilevel Statistical Models. 2nd edition. Kendall's Library of Statistics 3. Edward Arnold.

HARBISON, R.W. e HANUSHEK, E. A. (1992) Educational Performance of the Poor: Lessons from Rural Northeast Brazil. New York: Oxford University Press.

MENEZES-FILHO, Naércio e PAZELLO, Elaine T. (2004) "Does money in schools matter? Evaluating the effects of FUNDEF on wages and test scores in Brazil”. Seminários: Departamento de Economia, PUC-RIO. Maio. [http://www.econ.puc-rio.br/pdf/seminario/2004/fundef3.pdf]

RIBEIRO, M. B. e RODRIGUES Jr., W. (2006) “Eficiência do gasto público na América Latina”, Boletim de Desenvolvimento Fiscal, n. 3: 43-56.

RICE, N., JONES, A. (1997) "Multilevel models and health economics", Health Economics, v.6: 561--575. ROTHSTEIN, R. (2000) Introduction. The Class Size Policy Debate. Working Paper n. 121. Economics Policy Institute.

${ }^{11}$ OCDE. (2007). Education at a Glance 2007, OECD INDICATORS. 